\title{
Long-term outcomes of aortic root operations for Marfan syndrome: A comparison of Bentall versus aortic valve-sparing procedures
}

\author{
Joel Price, MD, MPH, ${ }^{\mathrm{a}} \mathrm{J}$. Trent Magruder, MD, ${ }^{\mathrm{a}}$ Allen Young, MPH, ${ }^{\mathrm{a}}$ Joshua C. Grimm, MD, ${ }^{\mathrm{a}}$ \\ Nishant D. Patel, MD, ${ }^{a}$ Diane Alejo, BA, ${ }^{a}$ Harry C. Dietz, MD, ${ }^{b}$ Luca A. Vricella, MD, ${ }^{a}$ and \\ Duke E. Cameron, $\mathrm{MD}^{\mathrm{a}}$
}

\begin{abstract}
Objectives: Prophylactic aortic root replacement improves survival in patients with Marfan syndrome with aortic root aneurysms, but the optimal procedure remains undefined.

Methods: Adult patients with Marfan syndrome who had Bentall or aortic valvesparing root replacement (VSRR) procedures between 1997 and 2013 were identified. Comprehensive follow-up information was obtained from hospital charts and telephone contact.
\end{abstract}

Results: One hundred sixty-five adult patients with Marfan syndrome (aged $>20$ years) had either VSRR $(\mathrm{n}=98 ; 69$ reimplantation, 29 remodeling) or Bentall $(n=67)$ procedures. Patients undergoing Bentall procedure were older (median, 37 vs 36 years; $P=.03$ ), had larger median preoperative sinus diameter $(5.5 \mathrm{~cm}$ vs $5.0 \mathrm{~cm} ; P=.003)$, more aortic dissections $(25.4 \%$ vs $4.1 \% ; P<.001)$, higher incidence of moderate or severe aortic insufficiency $(49.3 \%$ vs $14.4 \%$; $P<.001)$ and more urgent or emergent operations $(24.6 \%$ vs $3.3 \% ; P<.001)$. There were no hospital deaths and 9 late deaths in more than 17 years of follow-up (median, 7.8 deaths). Ten-year survival was $90.5 \%$ in patients undergoing Bentall procedure and $96.3 \%$ in patients undergoing VSRR $(P=.10)$. Multivariable analysis revealed that VSRR was associated with fewer thromboembolic or hemorrhagic events (hazard ratio, 0.16; 95\% confidence interval, 0.03-0.85; $P=.03$ ). There was no independent difference in long-term survival, freedom from reoperation, or freedom from endocarditis between the 2 procedures.

Conclusions: After prophylactic root replacement in patients with Marfan syndrome, patients undergoing Bentall and valve-sparing procedures have similar late survival, freedom from root reoperation, and freedom from endocarditis. However, valve-sparing procedures result in significantly fewer thromboembolic and hemorrhagic events. (J Thorac Cardiovasc Surg 2016;151:330-8)

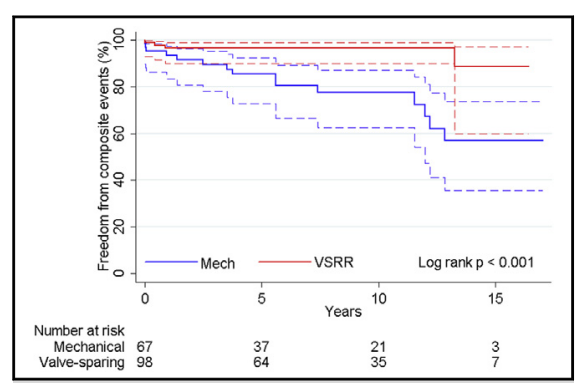

Freedom from composite thromboembolic/hemor rhagic events by procedure type.

\section{Central Message}

After prophylactic root replacement in patients with Marfan syndrome, patients undergoing Bentall and valve-sparing procedures have similar late survival.

\section{Perspective}

Prophylactic aortic root replacement improves survival in patients with Marfan syndrome with aortic root aneurysms, but the optimal procedure (Bentall vs valve-sparing aortic root replacement) remains undefined. We found that late survival is equivalent between the 2 procedures, although composite thromboembolic/hemorrhagic events are more common in patients undergoing Bentall procedure.

See Editorial Commentary page 339.

See Editorial page 291.
From the ${ }^{\mathrm{a} D i v i s i o n}$ of Cardiac Surgery and ${ }^{\mathrm{b}}$ Departments of Pediatrics, Medicine, Molecular Biology, and Genetics, The Johns Hopkins University School of Medicine, Baltimore, Md.

Funding: Dr Magruder is the Piccinini Fellow in cardiac surgical research at the Johns Hopkins Hospital. Dr Grimm is the Sharp Fellow in cardiac surgical research at the Johns Hopkins Hospital.

Read at the 95th Annual Meeting of The American Association for Thoracic Surgery, Seattle, Washington, April 25-29, 2015.

Received for publication May 1, 2015; revisions received Sept 23, 2015; accepted for publication Oct 6, 2015; available ahead of print Dec 15, 2015.

Address for reprints: Joel Price, MD, MPH, Division of Cardiac Surgery, The Johns Hopkins University School of Medicine, Zayed Tower 7107, 1800 Orleans St, Baltimore, MD 21287 (E-mail: jprice@jhmi.edu).

$0022-5223 / \$ 36.00$

Copyright (c) 2016 by The American Association for Thoracic Surgery

http://dx.doi.org/10.1016/j.jtcvs.2015.10.068
Dissection and rupture of the aortic root are the leading cause of death among patients with Marfan syndrome (MFS). ${ }^{1,2}$ MFS is due to genetic mutations in the FBN1 gene that lead to abnormal production and cellular handling of the fibrillin-1 protein. ${ }^{3}$ About four-fifths of all

Scanning this QR code will take you to the article title page. To view the AATS 2015 Webcast, see the URL at the end of the article. 


\section{Abbreviations and Acronyms \\ AI = aortic insufficiency \\ MFS = Marfan syndrome \\ VSRR $=$ valve-sparing root replacement}

patients with MFS develop annuloaortic ectasia, and many of these patients will progress to aortic valve regurgitation, congestive heart failure, and aortic dissection or rupture. ${ }^{2,4}$ These conditions contribute to a reduced life expectancy in patients with MFS. ${ }^{5,6}$ Before the advent of surgical intervention in these patients, 1 series $^{7}$ reported mean survival of about 44 years and most premature deaths were due to cardiovascular causes.

Survival in patients with MFS has been improved by introduction of prophylactic surgical aortic root replacement. ${ }^{6}$ The original method of repair described by Bentall and DeBono ${ }^{8}$ in 1968 involved replacement of the aortic root and aortic valve with a mechanical valve sutured to an aortic prosthesis. An alternative technique for aortic root replacement was described by Yacoub and colleagues, ${ }^{9}$ in which the native aortic valve was preserved. In the remodeling aortic valve-sparing root replacement (VSRR) procedure, the sinuses of Valsalva are replaced and the coronary arteries are reimplanted into the graft. The refinement of the VSRR technique proposed by David and Feindel ${ }^{10}$ described reimplantation of the native aortic valve complex within the aortic prosthesis, which prevents late dilation of the aortic annulus.

Conceptually, preservation of a normally functioning aortic valve is desirable in young patients to avoid lifelong anticoagulation therapy and other potential valve-related complications that accompany replacement with a mechanical aortic valve. In addition, bioprostheses in this group have disappointing durability. A number of centers have published good results for VSRR procedures in patients with MFS. ${ }^{11-16}$ However, use of VSRR operations in patients with MFS remains controversial due to concerns over the technical complexity of the operation and longterm durability of the native valve. MFS aortic valves have known defects in fibrillin-1 within aortic valve leaflets. ${ }^{3}$ Furthermore, if the aortic annulus is not fully supported, dilation and aortic regurgitation may occur over time. To date, there has been limited long-term follow-up of patients undergoing the operation and data directly comparing VSRR to mechanical composite valve-graft replacement are scant.

Because the question of the preferred treatment for patients with MFS with root aneurysm remains unsettled, we reviewed our results with patients with MFS who underwent the traditional Bentall procedure and compared them directly with patients who had a VSRR operation during the same period. The objective was to compare long-term survival and freedom from valverelated events.

\section{MATERIALS AND METHODS Study Design, Patient Selection, and Patient Variables}

The protocol was approved by our institutional review board and the need for individual informed consent was waived. We performed a chart review on all adult patients with MFS who underwent Bentall operations or VSRR at the Johns Hopkins Hospital between 1997 and 2014. Patients who received aortic root replacement with bioprosthetic valves were excluded. The diagnosis of MFS was made using the Ghent criteria for the diagnosis of MFS. ${ }^{17}$ These criteria were revised during the course of the study; the most recent guidelines in effect at the time of diagnosis were used. ${ }^{18}$ All patients underwent a preoperative transthoracic echocardiogram to assess aortic diameter and valve function. Intraoperative transesophageal and postoperative transthoracic echocardiograms were conducted, as well. Clinical follow-up data were obtained by telephone interview with the patient, family member, or primary care physician. All patients undergoing VSRR were advised to have an echocardiogram, computed tomography scan, or magnetic resonance imaging scan 6 months postoperatively and annually thereafter.

Variables collected on patients included demographic and comorbidity information; echocardiographic parameters, including aortic diameter and degree of aortic insufficiency (AI); operative data; and postoperative data, including complications and mortality. The primary outcomes of our study were long-term survival, a composite hematologic end point consisting of thromboembolic or hemorrhagic events, reoperation on the aortic valve or root, and endocarditis of the native or prosthetic aortic valve. All valve-related events were defined according to published guidelines. ${ }^{19}$

Clinical follow-up consisted of a detailed chart review in all patients and was $100 \%$ complete. This was supplemented with a thorough telephone interview that was completed in $70 \%$ of patients. Clinical follow-up was updated through August 2014. Preoperative and intraoperative echocardiographic data were collected for all patients. Follow-up echocardiographic examination was available for $84 \%$ of patients undergoing VSRR; median duration of echocardiographic follow-up was 2.0 years (interquartile range [IQR], 6 days-8.1 years). The median number of follow-up echocardiograms among patients undergoing VSRR was 2 (IQR, 1-6).

\section{Operative Technique}

Patients with MFS undergoing the Bentall operation received mechanical composite valve grafts using standard techniques. All procedures were performed using median sternotomy. Procedures were performed on cardiopulmonary bypass using moderate systemic hypothermia. Antegrade root and ostial cold cardioplegia were used. From 1997 to 2002, the 29 patients who underwent VSRR received a remodeling operation. Since 2002, all patients with MFS receiving VSRR underwent a reimplantation technique using a Vascutek Gelweave valsalva graft (Vascutek, a Terumo Company, Renfrewshire, Scotland). The VSRR technique employed in our institution has been described previously. ${ }^{20-22}$ At our institution, certain criteria are used to assess candidacy for VSRR. Relative contraindications for VSRR in patients with MFS include preoperative annular diameter $>34 \mathrm{~mm}$, significant leaflet fenestrations, significant leaflet asymmetry, acute dissection in unstable patients, or a very dilated root with significant leaflet irregularities. Patients with calcified bicuspid valves and prolapse, thickening, or fenestrations were also not offered VSRR. 


\section{Postoperative Care}

All patients undergoing VSRR received aspirin therapy for 1 month postoperatively as well as $\beta$-blocker therapy indefinitely. A predischarge echocardiogram was performed and annual follow-up exams were recommended. In recent years, many patients were also prescribed losartan, an angiotensin II type I receptor antagonist that has been shown to slow aortic aneurysmal growth. ${ }^{23}$ Patients who received Bentall procedures required lifelong sodium warfarin therapy. The target international normalized ratio was 2.0 to 3.0. Postdischarge care was directed by the patient's referring cardiologist.

\section{Statistical Analyses}

Statistical analyses were performed using Stata version 13.0 (StataCorp, College Station, Tex). Continuous preoperative and postoperative variables were compared using Student $t$ test and the rank-sum nonparametric test when the variable was skewed. The $\chi^{2}$ test or Fischer exact test (in the case of small numbers) was used to compare categorical variables. Linearized event rates were calculated as the number of events (eg, survival, composite bleeding and thrombosis, reoperations on the aortic valve or root, and diagnoses of endocarditis) divided by the number of patient-years of follow-up multiplied by $100 .{ }^{19}$ Survival and freedom from valve-related events outcomes were estimated using the Kaplan-Meier method, and univariable comparisons of the Bentall versus VSRR made with the log-rank test.

To adjust for differences in baseline patient characteristics between the groups, we performed a multivariable analysis consisting of propensity score-adjusted Cox proportional hazards modeling. Using a nonparsimonious logistic regression model for the outcome of procedure choice (VSRR vs Bentall), a propensity score was calculated for each patient. Variables included in the propensity score model included age, sex, race, hypertension, hyperlipidemia, preoperative atrial fibrillation, New York Heart Association functional class, ejection fraction, aortic sinus diameter, degree of $\mathrm{AI}$, urgent or emergent surgery, and the performance of any associated procedure during the operation. The C-statistic of the propensity score model was 0.8543 . Subsequent analysis involved construction of Cox proportional hazards models for each outcome, with the propensity score as the sole covariate. The proportional hazards assumption was confirmed with the construction of $\log -\log$ plots. Results are reported as hazard ratios (HRs) with corresponding $95 \%$ confidence intervals (CIs) and $P$ values. To compare the risk of developing aortic regurgitation in patients undergoing VSRR who underwent aortic root remodeling versus reimplantation,

TABLE 1. Baseline characteristics

\begin{tabular}{lccc}
\hline \multicolumn{1}{c}{ Characteristic } & Bentall & VSRR & $\boldsymbol{P}$ value \\
\hline $\mathrm{n}$ & 67 & 98 & - \\
Age (y) & $37(31-50)$ & $36(29-41)$ & .03 \\
Male gender & $40(61.5)$ & $66(72.5)$ & .17 \\
Hypertension & $16(23.9)$ & $12(12.2)$ & .05 \\
Hyperlipidemial & $15(22.4)$ & $37(37.8)$ & .04 \\
Preoperative atrial fibrillation & $1(1.8)$ & $3(4.6)$ & .40 \\
NYHA functional class III or IV & $26(38.8)$ & $8(8.2)$ & $<.001$ \\
Ejection fraction & $60(50-60)$ & $50(55-60)$ & .28 \\
Aortic diameter at sinuses (cm) & $5.5(5-6)$ & $5.0(4.9-5.3)$ & .003 \\
Bicuspid valve & $5(7.4)$ & $2(2.1)$ & .20 \\
Evidence of ascending dissection & $17(25.4)$ & $4(4.1)$ & $<.001$ \\
Moderate or severe AI & $33(49.3)$ & $14(14.4)$ & $<.001$ \\
Urgent or emergent operation & $16(24.6)$ & $3(3.3)$ & $<.001$ \\
\hline Var
\end{tabular}

Values are presented as median (interquartile range) or $\mathrm{n}(\%)$. VSRR, Valve-sparing root replacement; NYHA, New York Heart Association; $A I$, aortic insufficiency. we used a mixed-effects model with available longitudinal echocardiographic follow-up data.

\section{RESULTS}

A total of 182 adult patients with MFS underwent Bentall procedures or VSRR between April 1997 and June 2014 (Table 1). Seventeen patients who underwent composite valve-graft procedures with a biologic aortic valve were excluded, yielding a cohort of 165 patients. Median clinical follow-up was 7.8 years (IQR, 2.911.4 years); follow-up by operation type was 7.1 years for patients undergoing Bentall and 8.4 years for patients undergoing VSRR. Patients who underwent a Bentall procedure were significantly older (Bentall, 37 years vs VSRR, 36 years; $P=.03$ ), had a larger median aortic sinus diameter $(5.5$ vs $5.0 \mathrm{~cm} ; P=.003)$, more aortic dissections $(25.4 \%$ vs $4.1 \% ; P<.001)$, a higher incidence of moderate or severe AI $(49.3 \%$ vs $14.4 \%$; $P<.001$ ), and underwent more urgent or emergent operations $(24.6 \%$ vs $3.3 \% ; P<.001)$.

\section{Operative Data}

Table 2 shows operative data by procedure type. Sixty-seven patients underwent a Bentall procedure $(40.6 \%)$ and 98 underwent VSRR (59.4\%). For those who underwent VSRR, 29 patients had a remodeling procedure, and the most recent 69 had a reimplantation procedure. Bypass and crossclamp times were similar between patients undergoing Bentall and VSRR procedures. However, VSRR patients were more likely to have a concomitant patent foramen ovale closure or atrial septal defect repair at the time of surgery $(26.9 \%$ vs $44.3 \% ; P=.03)$, whereas Bentall patients were more likely to have a mitral valve replacement $(6.0 \%$ vs $0.0 \% ; P=.03)$.

\section{Postoperative Complications}

Postoperative complication rates were low and are shown in Table 3. The incidence of pneumothorax,

TABLE 2. Operative data

\begin{tabular}{lccc}
\hline \multicolumn{1}{c}{ Item } & Bentall & VSRR & $\boldsymbol{P}$ value \\
\hline Reimplantation & - & $69(70.4)$ & - \\
Remodeling & - & $29(29.6)$ & - \\
Mean crossclamp time (min) & $111.6 \pm 57.5$ & $104.2 \pm 19.1$ & .25 \\
Mean CPB time (min) & $158.8 \pm 78.0$ & $143.6 \pm 24.7$ & .08 \\
Concomitant procedures & & & \\
$\quad$ PFO closure/ASD repair & $18(26.9)$ & $43(44.3)$ & .03 \\
Mitral valve repair & $2(3.0)$ & $7(7.2)$ & .31 \\
Mitral valve replacement & $4(6.0)$ & 0 & .03 \\
CABG & $6(9.0)$ & $2(2.1)$ & .06 \\
\hline
\end{tabular}

Values are presented as mean \pm standard deviation or $\mathrm{n}(\%)$. VSRR, Valve-sparing root replacement; $C P B$, cardiopulmonary bypass; $P F O$, patent foramen ovale; $A S D$, atrial septal defect; $C A B G$, coronary artery bypass grafting. 
TABLE 3. Postoperative complications

\begin{tabular}{lccc}
\hline \multicolumn{1}{c}{ Complication } & Bentall & VSRR & $\boldsymbol{P}$ value \\
\hline In-hospital death & 0 & 0 & 1.00 \\
Cerebrovascular accident & 0 & 0 & 1.00 \\
Pneumothorax & $6(9.0)$ & $7(7.1)$ & .77 \\
Hemothorax & $2(3.0)$ & $1(1.0)$ & .57 \\
Reoperation for bleeding & $1(1.5)$ & $2(2.0)$ & 1.00 \\
Atrial fibrillation & $14(20.9)$ & $19(19.4)$ & .85 \\
\hline
\end{tabular}

Values are presented as $\mathrm{n}(\%)$. VSRR, Valve-sparing root replacement.

hemothorax, and atrial fibrillation were similar between the 2 groups. There was 1 reoperation for bleeding in the Bentall group and 2 in the VSRR group $(1.5 \%$ vs $2.0 \% ; P=1.00)$. There were no cerebrovascular accidents in either group while in the hospital $(P=1.00)$. There was no in-hospital mortality.

\section{Long-Term Outcomes}

There were 9 late deaths in more than 17 years of followup. Survival at 10 years was $90.5 \% \pm 4.1 \%$ in Bentall patients and $96.3 \% \pm 2.7 \%$ in patients undergoing VSRR (Figure 1, A) and statistically similar between groups (log rank $P=.10$ ). A propensity score-adjusted Cox model confirmed that there was no independent effect of procedure choice on long-term survival (HR, 0.62; 95\% CI, 0.07-5.48; $P=.67)$.

Composite thromboembolic and/or hemorrhagic events occurred in 19 patients (Figure 1, B) (15 Bentall vs 4 VSRR; $\log$ rank $P<.001)$. In the Bentall group, there were 7 hemorrhagic events ( 3 intracranial hemorrhages, 2 gastrointestinal bleeds, and 2 other) and 8 thromboembolic events ( 6 cerebrovascular accidents, 1 acute arterial thrombosis of the leg, and 1 thrombosis of the aortic valve prosthesis). In the VSRR group, there were no hemorrhagic events and 4 thromboembolic events (4 cerebrovascular accidents). Ten-year freedom from composite events was $77.6 \% \pm 6.2 \%$ in the Bentall group and $96.7 \% \pm 1.9 \%$ in VSRR group (log rank $P<.001)$. The propensity score-adjusted regression analysis confirmed that VSRR was independently associated with greater long-term freedom from combined thromboembolic and/or hemorrhagic events (HR, 0.16; 95\% CI, 0.03-0.85; $P=.03$ ).

Eight patients required aortic valve or root reoperations over the course of follow-up. Four Bentall patients underwent reoperation compared with 4 patients undergoing VSRR ( $\log$ rank $P=.52$ ). In the Bentall group, 2 patients underwent redo aortic root replacements with homograft for prosthetic valve endocarditis, and 2 underwent aortic valve replacements ( 1 for valve thrombosis and 1 for aortic regurgitation). In the VSRR group, 2 patients had their aortic valves replaced for worsening aortic regurgitation, 1 patient underwent revision of his proximal ascending prosthesis during replacement of the aortic arch, and 1
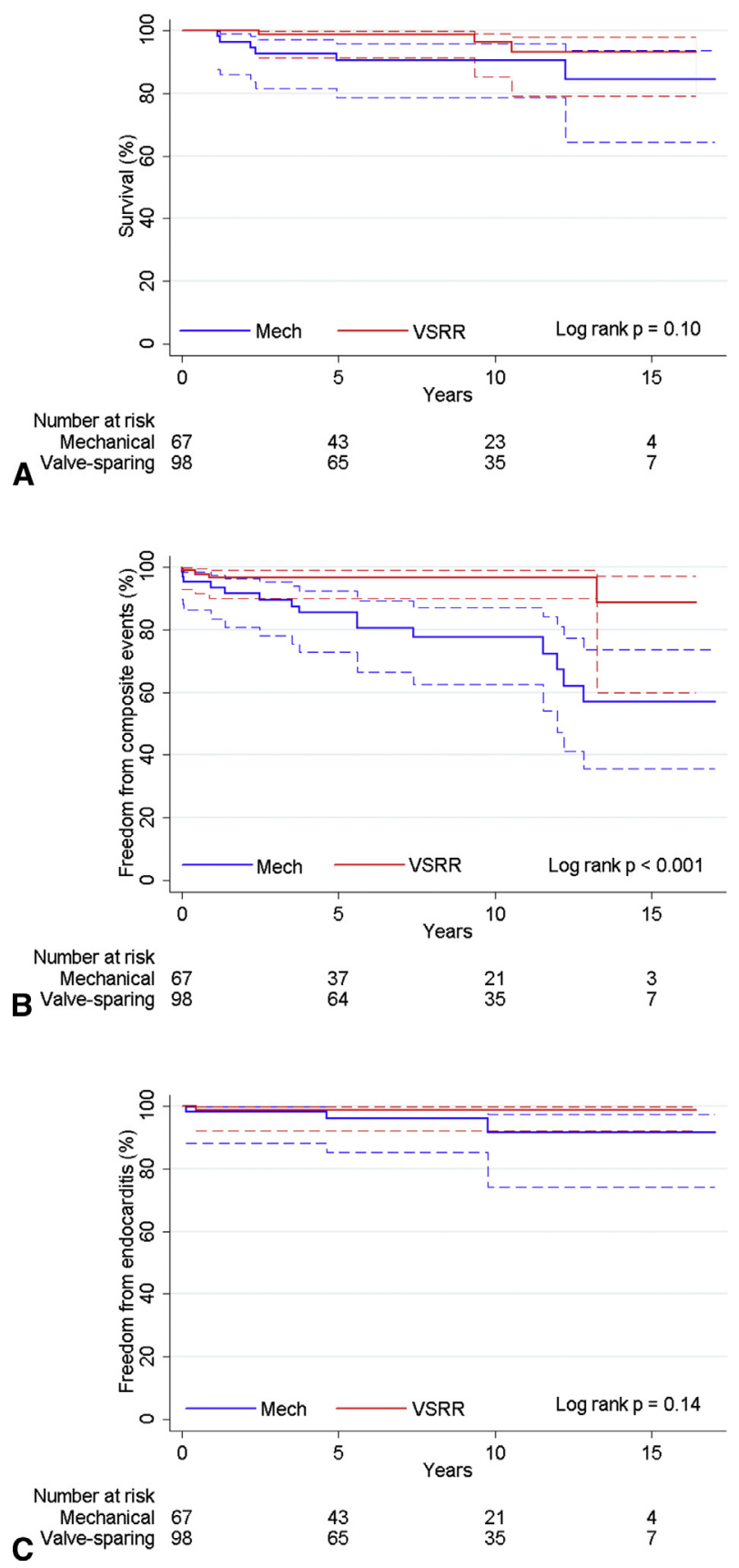

FIGURE 1. A, Comparison of overall survival between patients with Marfan syndrome undergoing mechanical Bentall procedure (Mech) versus valve-sparing root replacement (VSRR). B, Comparison of freedom from composite thromboembolic/hemorrhagic events according to a standardized definition between patients with Marfan syndrome undergoing Mech versus VSRR. C, Comparison of freedom from aortic valve endocarditis between patients with Marfan syndrome undergoing Mech versus VSRR.

underwent aortic valve replacement for endocarditis. Both reoperations for recurrent aortic regurgitation were performed in patients who originally underwent a remodeling operation. Ten-year freedom from reoperation was $92.0 \% \pm 3.9 \%$ in the Bentall group and $92.9 \% \pm 3.5 \%$ 

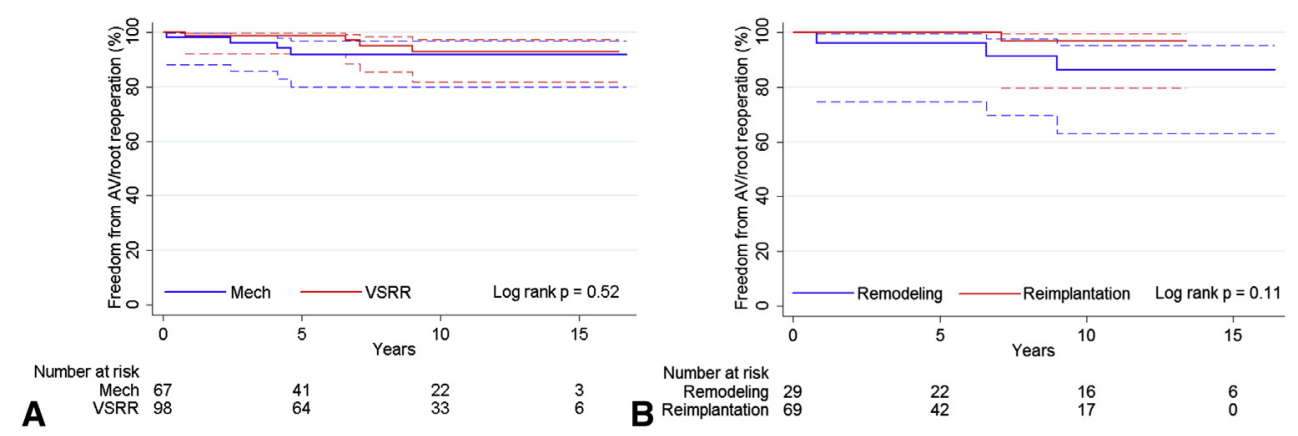

FIGURE 2. A, Comparison of freedom from reoperation on the aortic valve $(A V)$ and/or root between patients with Marfan syndrome undergoing mechanical Bentall procedure $(\mathrm{Mech})$ versus valve-sparing root replacement (VSRR). B, Comparison of freedom from reoperation on the AV and/or root between patients with Marfan syndrome undergoing prophylactic root replacement via either a remodeling or reimplantation technique.

in the VSRR group (Figure 2, $A$ ). The linearized risk of reoperation was $0.86 \%$ per patient year in the Bentall group and $0.56 \%$ in the VSRR group. The propensity scoreadjusted analysis confirmed that there was no independent difference in freedom from reoperation between treatment groups (HR, 1.21; 95\% CI, 0.14-10.28; $P=.86$ ). Among patients undergoing VSRR only 1 patient with a reimplantation procedure underwent a reoperation compared with 3 in the remodeling group (log rank $P=.11)$. This corresponds to a freedom from reoperation rate at 10 years of $96.9 \% \pm 3.1 \%$ in the reimplantation group and $86.4 \% \pm 7.4 \%$ in the remodeling group (Figure 2, B). Over the course of echocardiographic follow-up, $>1+$ aortic regurgitation was more common in remodeling patients than in reimplantation patients (odds ratio, 0.11; 95\% CI, 0.01-0.99; $P=.05$ ).

Aortic valve endocarditis was rare in our series. It occurred in 3 patients undergoing a Bentall procedure and 1 undergoing a VSRR procedure (log rank $P=.14$ ). This corresponded to a 10-year freedom from aortic endocarditis rate of $91.7 \% \pm 5.0 \%$ in Bentall patients and $98.9 \% \pm 1.0 \%$ in VSRR patients (Figure $1, C$ ). The linearized annual risk of aortic endocarditis was $0.17 \%$ in patients undergoing a Bentall procedure and $0.04 \%$ in patients undergoing VSRR.

\section{DISCUSSION}

The Bentall operation was first described almost 5 decades ago and has remained the standard of care in patients with MFS with aortic root aneurysms and the benchmark to which long-term results of VSRR must be compared. $^{22,24,25}$ Here, we report the results of our comparative series of patients with MFS undergoing aortic root replacement. This study was performed during the contemporary era (1997-2014) when both the Bentall operation and VSRR were offered at our institution. As such, the study provides more than 15 years of data to compare the 2 procedures in a large cohort of patients with MFS. We observed excellent perioperative and long-term outcomes for both procedures. To date, we have observed no operative mortality in any patient with MFS requiring an aortic root replacement. Patients with MFS undergoing VSRR experienced superior freedom from bleeding/thromboembolism and equivalent long-term survival and durability compared with patients undergoing the Bentall procedure. Whereas a number of large centers have reported experience with the VSRR procedure in patients with MFS, there are few studies that directly compare results of VSRR and Bentall procedures in this population. In an important prospective, multicenter, comparative study, Coselli and colleagues ${ }^{26}$ reported operative and 1-year results of 77 patients undergoing Bentall procedures and 239 patients undergoing VSRR procedures performed in 19 centers. The authors ${ }^{26}$ found no independent difference in survival or freedom from major adverse valve-related events between the 2 procedures at 1 year. However, the authors reported $2+$ or greater aortic regurgitation in $7 \%$ of patients undergoing VSRR compared with none in the patients undergoing the Bentall procedure $(P=.02)$.

Concerns over long-term durability of VSRR were also raised in a meta-analysis performed by Benedetto and colleagues. ${ }^{27}$ The analysis included 11 studies and 1385 patients with MFS undergoing either Bentall or VSRR procedure. VSRR was associated with a 4-fold increase in the linearized rate of reintervention per year compared with Bentall procedures $(1.3 \%$ per year vs $0.3 \%$ per year: $P=.02)$. Similar to our findings, VSRR was associated with fewer thromboembolic events $(0.3 \%$ per year vs $0.7 \%$ per year; $P=.01$ ).

The results of the studies by Benedetto and colleagues ${ }^{27}$ and Coselli and colleagues ${ }^{26}$ highlight potential concerns regarding long-term durability of VSRR. Although we observed only 1 remodeling VSRR with significant AI and no increase in the reoperation rate for patients with VSRR, both of the above-mentioned studies have high external validity because they reflect results from multiple centers and surgeons. Numerous single-center series have 
reported excellent results similar to our own. In a comparative study, De Oliveira and colleagues ${ }^{14}$ reported similar 10 -year survival and freedom from reoperation in patients undergoing Bentall and VSRR procedures. ${ }^{14}$ Ten-year freedom from valve-related adverse events was superior for patients undergoing VSRR. However, freedom from $>2+$ aortic insufficiency at 8 years was $75 \%$. In a 2009 update of the series presented by David and colleagues, ${ }^{12}$ excellent survival and freedom from reoperation at 15 years was reported. Freedom from greater-than-mild AI was $79.2 \%$ at 15 years in this series.

We noted an increased incidence of reoperation in patients undergoing remodeling compared with reimplantation procedures. This finding did not achieve statistical significance, likely because of a small sample size and infrequent occurrence of the outcome. In comparison to the remodeling technique, reimplantation is more technically challenging for the surgeon. However, reimplantation technique externally fixes the entire aortic valve complex within the tube graft, theoretically preventing late dilation of the aortic annulus and minimizing the risk of subsequent valve failure. Before 2002, we favored the remodeling technique because it allows for preservation of the sinuses, which minimizes valve leaflet stress and allows optimal aortic root function. ${ }^{28-31}$ Our initial experience with the remodeling technique yielded patients who developed $\mathrm{AI}$ and required late valve replacement, usually due to annular dilation..$^{32,33}$ Concerns regarding late dilation and AI following the remodeling procedure have been voiced by a number of authors. ${ }^{12,27,34}$ The meta-analysis by Benedetto and colleagues $^{27}$ found that the reimplantation technique reduced the rate of reintervention compared with the remodeling technique $(0.7 \%$ per year vs $2.4 \%$ per year; $P=.02)$. Since 2002 we have moved exclusively to a modification of the David reimplantation for VSRR in patients with MFS. We do not recommend the use a remodeling technique in patients with connective tissue disorder.

We continue to use a modification of the reimplantation technique, with 3 pledgeted sutures placed below the nadir of each leaflet and a Valsalva graft as the conduit. $^{21,22}$ The use of the Valsalva graft, with its prefashioned sinuses, allows for a reasonable approximation of the natural anatomic configuration of the $\operatorname{root}^{35-38}$ and allows for external fixation of the annulus. We have found that this simplified technique makes the operation efficient and reproducible. If there is prolapse, it is treated by plication of the free-margin or occasionally free-margin resuspension with polytetrafluoroethelene suture. However, most patients with moderate or severe AI in our series underwent a Bentall operation. Similarly, VSRR can be performed in patients with MFS with a bicuspid aortic valve; however, these patients must be carefully selected. Patients with calcified bicuspid valves, thickening, or severe fenestrations are not good candidates for VSRR. Only 2 patients with bicuspid aortic valve underwent VSRR in our series. The incidence of endocarditis was very low for both procedures in our series. After VSRR we recommend lifelong antibiotic prophylaxis before dental and other invasive procedures.

This study has the limitations inherent in a retrospective analysis. Our groups differed significantly in terms of baseline characteristics. The comparison of postoperative complications was not risk-adjusted. For the main outcomes, we used propensity score-adjusted Cox models in an attempt to adjust for these differences. This technique was selected due to the low numbers of events in the cohort. However, given the retrospective design of this study, there is the potential that unmeasured confounders influenced the findings. The diagnostic criteria for MFS changed during the course of the study. The 2010 revised Ghent criteria for the diagnosis of MFS and related conditions include genetic testing for causal mutations in the FBNl gene. ${ }^{18}$ Although this has become part of our contemporary workup for these patients, this was not consistently the case early in the experience. The absence of genetic testing in all patients is a limitation of this study and there is the potential for some misclassification as a result. Data on the frequency and type of leaflet repair were inconsistently available in our database. As such, we are unable to report detailed information on concomitant leaflet repair. Echocardiographic follow-up in the VSRR group was relatively limited. The analysis of recurrent aortic regurgitation should be considered exploratory.

\section{CONCLUSIONS}

Prophylactic aortic root replacement using either the Bentall or VSRR procedures can be performed in patients with MFS with aortic root aneurysms with good results perioperatively and over the long term. The 2 procedures have similar adjusted late survival, freedom from root reoperation, and freedom from endocarditis. However, valve-sparing procedures result in significantly fewer thromboembolic and hemorrhagic events. We continue to favor the reimplantation technique for VSRR. These results support continued use of valve-sparing procedures in patients with MFS when possible to avoid anticoagulation-related complications associated with mechanical valves.

\section{Conflict of Interest Statement}

Authors have nothing to disclose with regard to commercial support.

You can watch a Webcast of this AATS meeting presentation by going to: http://webcast.aats.org/2015/Video/ Tuesday/04-28-15_612_1400_Price.mp4. 


\section{References}

1. Judge DP, Dietz HC. Marfan's syndrome. Lancet. 2005;9501:1965-76.

2. Marsalese DL, Moodie DS, Vacante M, Lytle BW, Gill CC, Sterba R, et al. Marfan's syndrome: natural history and long-term follow-up of cardiovascular involvement. J Am Coll Cardiol. 1989;2:422-8; discussion 429-1.

3. Fleischer KJ, Nousari HC, Anhalt GJ, Stone CD, Laschinger JC. Immunohistochemical abnormalities of fibrillin in cardiovascular tissues in Marfan's syndrome. Ann Thorac Surg. 1997;4:1012-7.

4. Roman MJ, Rosen SE, Kramer-Fox R, Devereux RB. Prognostic significance of the pattern of aortic root dilation in the Marfan syndrome. J Am Coll Cardiol. 1993;5:1470-6.

5. Groenink M, Lohuis TA, Tijssen JG, Naeff MS, Hennekam RC, van der Wall EE, et al. Survival and complication free survival in Marfan's syndrome: implications of current guidelines. Heart. 1999;4:499-504.

6. Silverman DI, Burton KJ, Gray J, Bosner MS, Kouchoukos NT, Roman MJ, et al. Life expectancy in the Marfan syndrome. Am J Cardiol. 1995;2: 157-60.

7. Murdoch JL, Walker BA, Halpern BL, Kuzma JW, McKusick VA. Life expectancy and causes of death in the Marfan syndrome. N Engl J Med. 1972;15:804-8.

8. Bentall H, De Bono A. A technique for complete replacement of the ascending aorta. Thorax. 1968;4:338-9.

9. Yacoub M, Fagan A, Stassano P, Radley-Smith R. Results of valve conserving operations for aortic regurgitation [abstract]. Circulation. 1983; 68(Suppl III):321.

10. David TE, Feindel CM. An aortic valve-sparing operation for patients with aortic incompetence and aneurysm of the ascending aorta. J Thorac Cardiovasc Surg. 1992;4:617-21; discussion 622.

11. Bernhardt AM, Treede H, Rybczynski M, Sheikzadeh S, Kersten JF, Meinertz T, et al. Comparison of aortic root replacement in patients with Marfan syndrome. Eur J Cardiothorac Surg. 2011;5:1052-7.

12. David TE, Armstrong S, Maganti M, Colman J, Bradley TJ. Long-term results of aortic valve-sparing operations in patients with Marfan syndrome. J Thorac Cardiovasc Surg. 2009;4:859-64; discussion 863-4.

13. David TE, Feindel CM, David CM, Manlhiot C. A quarter of a century of experience with aortic valve-sparing operations. J Thorac Cardiovasc Surg. 2014;3 872-9; discussion 879-80.

14. de Oliveira NC, David TE, Ivanov J, Armstrong S, Eriksson MJ, Rakowski H, et al. Results of surgery for aortic root aneurysm in patients with Marfan syndrome. J Thorac Cardiovasc Surg. 2003;4:789-96.

15. Kvitting JP, Kari FA, Fischbein MP, Liang DH, Beraud AS, Stephens EH, et al David valve-sparing aortic root replacement: equivalent mid-term outcome for different valve types with or without connective tissue disorder. $J$ Thorac Cardiovasc Surg. 2013;1:117-26. 127.e1-5; discussion 126-7.

16. Svensson LG, Blackstone EH, Alsalihi M, Batizy LH, Roselli EE, McCullough R, et al. Midterm results of David reimplantation in patients with connective tissue disorder. Ann Thorac Surg. 2013;2:555-62.

17. De Paepe A, Devereux RB, Dietz HC, Hennekam RC, Pyeritz RE. Revised diagnostic criteria for the Marfan syndrome. Am J Med Genet. 1996;4:417-26.

18. Loeys BL, Dietz HC, Braverman AC, Callewaert BL, De Backer J, Devereux RB, et al. The revised Ghent nosology for the Marfan syndrome. J Med Genet. 2010 7:476-85.

19. Akins CW, Miller DC, Turina MI, Kouchoukos NT, Blackstone EH, Grunkemeier GL, et al. Guidelines for reporting mortality and morbidity after cardiac valve interventions. J Thorac Cardiovasc Surg. 2008;4:732-8.

20. Cameron DE, Vricella LA. Valve-sparing aortic root replacement in Marfan syndrome. Semin Thorac Cardiovasc Surg Pediatr Card Surg Annu. 2005;103-11.

21. Patel ND, Williams JA, Barreiro CJ, Bethea BT, Fitton TP, Dietz HC, et al. Valvesparing aortic root replacement: early experience with the De Paulis Valsalva graft in 51 patients. Ann Thorac Surg. 2006;2:548-53.

22. Cameron DE, Vricella LA. Valve-sparing aortic root replacement with the Valsalva graft. Oper Tech Thorac Cardiovasc Surg. 2009;4:297-308.

23. Groenink M, den Hartog AW, Franken R, Radonic T, de Waard V, Timmermans J, et al. Losartan reduces aortic dilatation rate in adults with Marfan syndrome: a randomized controlled trial. Eur Heart J. 2013;45:3491-500.

24. Gott VL, Cameron DE, Alejo DE, Greene PS, Shake JG, Caparrelli DJ, et al Aortic root replacement in 271 Marfan patients: a 24-year experience. Ann Thorac Surg. 2002;2:438-43.

25. Gott VL, Greene PS, Alejo DE, Cameron DE, Naftel DC, Miller DC, et al Replacement of the aortic root in patients with Marfan's syndrome. $N$ Engl J Med. 1999;17:1307-13.
26. Coselli JS, Volguina IV, LeMaire SA, Sundt TM, Connolly HM, Stephens EH, et al. Early and 1-year outcomes of aortic root surgery in patients with Marfan syndrome: a prospective, multicenter, comparative study. J Thorac Cardiovasc Surg. 2014;147:1758-66. 1767.e1-4.

27. Benedetto U, Melina G, Takkenberg JJ, Roscitano A, Angeloni E, Sinatra R Surgical management of aortic root disease in Marfan syndrome: a systematic review and meta-analysis. Heart. 2011;12:955-8.

28. Bellhouse BJ, Reid KG. Fluid mechanics of the aortic valve. Br Heart J. 1969;3: 391

29. Grande-Allen KJ, Cochran RP, Reinhall PG, Kunzelman KS. Re-creation of sinuses is important for sparing the aortic valve: a finite element study. $J$ Thorac Cardiovasc Surg. 2000;4(Pt 1):753-63.

30. Leyh RG, Schmidtke C, Sievers HH, Yacoub MH. Opening and closing characteristics of the aortic valve after different types of valve-preserving surgery. Circulation. 1999;21:2153-60.

31. Thubrikar MJ, Nolan SP, Aouad J, Deck JD. Stress sharing between the sinus and leaflets of canine aortic valve. Ann Thorac Surg. 1986;4:434-40.

32. Bethea BT, Fitton TP, Alejo DE, Barreiro CJ, Cattaneo SM, Dietz HC, et al Results of aortic valve-sparing operations: experience with remodeling and reimplantation procedures in 65 patients. Ann Thorac Surg. 2004;3:767-72; discussion 767-72.

33. Patel ND, Weiss ES, Alejo DE, Nwakanma LU, Williams JA, Dietz HC, et al. Aortic root operations for Marfan syndrome: a comparison of the Bentall and valve-sparing procedures. Ann Thorac Surg. 2008;6:2003-10; discussion 2010-11.

34. David TE, Armstrong S, Ivanov J, Feindel CM, Omran A, Webb G. Results of aortic valve-sparing operations. J Thorac Cardiovasc Surg. 2001;1:39-46.

35. De Paulis R, De Matteis GM, Nardi P, Scaffa R, Bassano C, Chiariello L. Analysis of valve motion after the reimplantation type of valve-sparing procedure (David I) with a new aortic root conduit. Ann Thorac Surg. 2002;1:53-7.

36. De Paulis R, De Matteis GM, Nardi P, Scaffa R, Colella DF, Bassano C, et al One-year appraisal of a new aortic root conduit with sinuses of Valsalva. J Thorac Cardiovasc Surg. 2002:1:33-9.

37. De Paulis R, De Matteis GM, Nardi P, Scaffa R, Colella DF, Chiarello L. A new aortic Dacron conduit for surgical treatment of aortic root pathology. Ital Heart J 2000;7:457-63

38. Pacini D, Settepani F, De Paulis R, Loforte A, Nardella S, Ornaghi D, et al. Early results of valve-sparing reimplantation procedure using the Valsalva conduit: multicenter study. Ann Thorac Surg. 2006;3:865-71; discussion 871-2.

Key Words: aortic root replacement, aortic valve-sparing root replacement, Marfan syndrome

\section{Discussion}

Dr Thomas Gleason (Pittsburgh, $\mathrm{Pa}$ ). That was an excellent presentation. I want to commend your group for doing such quality work. I do have a few questions.

First, the results of the regression analysis are not surprising; notably, that the difference in thromboembolic and hemorrhagic events was higher in the composite group. But I'm not sure that is completely relevant despite the propensity matching. I say that because the Bentall patients clearly had larger-diameter aortas, considerably more dissections, and considerably more aortic insufficiency. Thus, these were all indications for significant selection bias.

In that light, what is the real take-home message for those patients? Are you suggesting that those patients should have undergone a valve-sparing root procedure instead of a Bentall?

Your results with both techniques were excellent, so one could also argue that the Bentall procedure should be used in those cases over a valve-sparing root procedure. How do you settle that? 
On the other hand, I note that your crossclamp times were actually shorter in the valve-sparing group. Although not statistically significant, they were shorter than in the composite group. That may mean that the dissection patients were the best candidates, and yet it seems that you are arguing the opposite. In fact, presenting that composite use might be better in that population.

Third, could you please be a little more specific with regard to echocardiographic follow-up? You state that you had a $100 \%$ follow-up, but you also clarify that $70 \%$ had telephone contact. How many patients actually had echocardiograms beyond the 2-year mark, and what was the level of aortic insufficiency 1, 2, and 3 years beyond that 2-year follow-up, because that is really an important metric for the valve-sparing group, not just reoperation rate at the 7-year mark.

Dr Price. I appreciate the questions, Dr Gleason. I'll answer them 1 at a time.

Your first question is regarding the type of statistical analysis and the interpretation. You correctly point out that we were quite selective about the patients in whom we performed a valve-sparing root procedure. They were less likely to have aortic dissection, they were less likely to be an urgent or emergent operation, and they had smaller sinuses.

To speak to the statistical issue first, it is challenging to find an appropriate multivariable technique because it is a relatively small group, and when speaking about a Cox model, the number of events was small. Our solution was to create a nonparsimonious logistic regression model predicting the type of procedure and then using that model to create a propensity score. We then used the propensity score as a sole covariate in a Cox proportional hazards model.

The predictive ability of that model is limited by the logistic regression model's ability to predict choice of procedure.

Like any regression technique, it is imperfect and there certainly is the potential for uncontrolled confounders. Your criticisms are very well taken.

To speak to your point about whether I advocate using a valve-sparing root in some of the patients who received a Bentall, the answer is generally no. We are unapologetically selective about the patients in whom the valve-sparing root is performed.

I think 1 message from our data is that by appropriately selecting patients, one can achieve excellent results. For patients in whom the leaflets are inappropriate, the sinuses are extraordinarily large, or who present with acute needs, those patients are probably better served by a Bentall procedure.

Regarding the echocardiographic follow-up, as you correctly said, the clinical follow-up was $100 \%$ complete in terms of our database and our medical record review. We supplemented those data with a telephone interview, which was completed in about $70 \%$ of patients.
The echocardiographic data, unfortunately, were not quite as good. The median follow-up for echocardiographic data was approximately 2 years, and in our population, the performance of echocardiography was not protocol-driven, so there is an inherent bias in that.

Also, the interquartile range for the median duration of follow-up for echocardiographic data was very wide, so we had some short-term and some very-long-term echocardiography data. Certainly as time and the duration of follow-up went on, the number of echocardiograms performed went down. As such, the discriminative power certainly is decreased, and that is an inherent limitation of this study.

With respect to crossclamp time, that issue is somewhat confounded by a number of other factors. First, there were a lot of concomitant procedures, and the patients who underwent a Bentall procedure were more likely to have a concomitant procedure that significantly extended the crossclamp time.

The second confounding issue is the surgeon performing the procedure. With respect to the valve-sparing root replacement, those were essentially all performed by $\mathrm{Dr} \mathrm{Ca}-$ meron. But the composite valve grafts were performed by a number of different surgeons, so there is another source of confounding.

Dr Gleason. I have 1 more question, and this I find to be intriguing. Seven patients in the whole series had bicuspid valves and had Marfan syndrome. That is an overall percentage of $4 \%$.

We see a lot of patients with bicuspid valves, but we do not see this frequency of bicuspid anatomy among the patients with Marfan syndrome. Were all the patients with Marfan syndrome genetically tested? Were you also struck by the frequency of bicuspid anatomy?

Dr Price. That's an important point. I appreciate you bringing it up.

With respect to the diagnosis of Marfan syndrome, the vast majority of patients were screened in our institutional Marfan clinic, which is headed by Dr Hal Dietz. As you know, Dr Dietz has continued to play an important role of the development of the diagnostic criteria for Marfan syndrome.

In addition, Dr Dietz and our Marfan clinic actually served as the diagnostic core lab for the Aortic Valve Operative Outcomes in Marfan Patients Study Group that has recently published its 1-year outcomes. As such, we feel fairly confident that the diagnoses were very well vetted.

You bring up the important point that there was an unusually high incidence of bicuspid valve anatomy. Of course, one would expect an incidence of $1 \%$ to $2 \%$, the same as the general population, in patients with Marfan syndrome. In our study we observed a rate of $4 \%$. I do not believe that this is an issue of misdiagnosis, meaning we incorrectly diagnosed bicuspid patients as Marfan syndrome patients. It 
is a peculiarity of our dataset. I do not have an excellent explanation for you, but I agree that it is remarkable and it is certainly a higher incidence of bicuspid valve anatomy than one might expect.

Dr Scott A LeMaire (Houston, Tex). To follow-up on the diagnosis issue, many patients that we identified as having Marfan syndrome in 1997 wouldn't meet diagnostic criteria today. Did you select your group based on their original diagnosis at the time of their operation, or were the patients reclassified based on what we've learned over the last 20 years about some of the other diagnoses?

Dr Price. Of course you are referring to issues of, for example, transforming growth factor- $\beta$ receptor mutations being diagnosed as Marfan syndrome at that time. This is a potential source of error, in that we did not reassess the diagnosis for our investigation. In other words, the diagnosis that was made at the time of the operation was what was used to stratify patients.

Certainly there is potential for misclassification; patients who turned out to have Loeys-Dietz, for example, were mistakenly classified as having Marfan syndrome.

Dr Andreas Martens (Hannover, Germany). Thank you for that nice talk. I have a question regarding the long-term follow-up on the primary surgery procedure in the valvesparing root procedure. Because we know that if you do leaflet repair in addition to the valve-sparing root repair, the outcome might be worse.

Do you have any information of how many leaflet repairs you did in that kind of series, because those patients who receive a lot of leaflet repair might be the best candidates to have a Bentall procedure in the beginning.

Dr Price. That is a very important point. We did not specifically show the leaflet data because they were not reliably captured in our database. Anecdotally, in our series the incidence of leaflet repairs is approximately $10 \%$ to $20 \%$. When necessary, we perform it by way of a central leaflet freemargin plication.

So we are, as we have pointed out, quite selective about the patients with Marfan syndrome who will undergo a valve-sparing root procedure. Certainly patients with significant leaflet fenestrations, very large sinuses, stretched leaflets, or any degree of calcification or fibrosis, we would tend not perform a valve-sparing root and leaflet repair procedure.

Therefore, we believe the patients in whom we do perform a leaflet repair are excellent candidates and we believe that the repair will have good long-term durability. Certainly that has been borne out in our results.

The data support our approach. If you look at a number of series, Dr El Khoury's data, for example, have demonstrated if you add a leaflet repair to a valve-sparing root procedure, you actually do not negatively affect the durability of the repair. I know that this is a controversial issue, but the underlying reason for that is patient selection; if you really select these leaflets and patients well, you can add an appropriate leaflet repair and not adversely affect long-term durability.

Dr Edward P. Chen (Atlanta, $G a$ ). I want to ask you a little bit more about the dissection in the valve-sparing procedure. Of course, we have an institutional bias toward performing valve-sparing operations in the setting of dissection, and in expert hands such as yours it can certainly be done very safely.

So if you have a patient with Marfan syndrome presenting with a type A dissection who is very young, are you automatically going to do a mechanical Bentall composite graft, or is there any consideration for doing a David procedure?

Dr Price. A patient with type A aortic dissection will not automatically receive a composite valve graft. Certainly I do think the threshold changes.

Factors such as the size of the root and the quality of the leaflets will be more heavily scrutinized in the setting of a type A dissection. As you saw in our data, there were a number of patients who did have type A dissection and did receive a valve-sparing root procedure. So type A dissection is not a contraindication to the valve-sparing root procedure. It does, however, require significant experience and excellent judgment.

Dr Chen. Thank you. 